\title{
Testing the Hypothesis that the MJO is a Mixed Rossby-Gravity Wave Packet
}

\author{
DA YANG AND ANDREW P. INGERSOLL \\ Division of Geological and Planetary Sciences, California Institute of Technology, Pasadena, California
}

(Manuscript received 25 May 2010, in final form 24 September 2010)

\begin{abstract}
The Madden-Julian oscillation (MJO), also known as the intraseasonal oscillation (ISO), is a planetaryscale mode of variation in the tropical Indian and western Pacific Oceans. Basic questions about the MJO are why it propagates eastward at $\sim 5 \mathrm{~m} \mathrm{~s}^{-1}$, why it lasts for intraseasonal time scales, and how it interacts with the fine structure that is embedded in it. This study will test the hypothesis that the MJO is not a wave but a wave packet - the interference pattern produced by a narrow frequency band of mixed Rossby-gravity (MRG) waves. As such, the MJO would propagate with the MRG group velocity, which is eastward at $\sim 5 \mathrm{~m} \mathrm{~s}^{-1}$. Simulation with a 3D model shows that MRG waves can be forced independently by relatively short-lived, eastward- and westward-moving disturbances, and the MRG wave packet can last long enough to form the intraseasonal variability. This hypothesis is consistent with the view that the MJO is episodic, with an irregular time interval between events rather than a periodic oscillation. The packet is defined as the horizontally smoothed variance of the MRG wave-the rectified MRG wave, which has features in common with the MJO. The two-dimensional Fourier analysis of the NOAA outgoing longwave radiation (OLR) dataset herein indicates that there is a statistically significant correlation between the MJO amplitude and wave packets of MRG waves but not equatorial Rossby waves or Kelvin waves, which are derived from the Matsuno shallow water theory. However, the biggest absolute value of the correlation coefficient is only 0.21 , indicating that the wave packet hypothesis explains only a small fraction of the variance of the MJO in the OLR data.
\end{abstract}

\section{Introduction}

The Madden-Julian oscillation (MJO) is the dominant intraseasonal variability in the tropical atmosphere. It is a planetary-scale, slowly eastward-propagating (about $5 \mathrm{~m} \mathrm{~s}^{-1}$ ) perturbation of both dynamical and thermodynamical fields. During an MJO event, a positive convection and rainfall anomaly develops in the western Indian Ocean and propagates to the western Pacific Ocean. Once the perturbation reaches the date line, the perturbation is largely confined to dynamical fields. The associated planetary-scale wind structure is baroclinic and is characterized by low-level convergence and upperlevel divergence (Madden and Julian 1972, 1994; Hendon and Salby 1994). More details can be found in recent and comprehensive reviews (e.g., Madden and Julian 2005; Zhang 2005). In addition, within the MJO envelope, there are both westward- and eastward-moving fine-scale

\footnotetext{
Corresponding author address: Da Yang, Division of Geological and Planetary Sciences, 150-21, California Institute of Technology, Pasadena, CA 91125.

E-mail: dyang@caltech.edu
}

structures (Nakazawa 1988; Hendon and Liebmann 1994).

The significance of the MJO for phenomena such as monsoon onset, ENSO, and rainfall patterns in the tropics has been well established (Lau and Waliser 2005; Zhang 2005). However, a successful MJO theory, which accounts for all of the above features, is elusive. General circulation models (GCMs) simulate tropical intraseasonal variability with varying degrees of fidelity. Intercomparison studies (Lin et al. 2006; Zhang et al. 2006) show that most GCMs underestimate the variance associated with the MJO. Because of the complexity of GCMs, simple models can provide suggestions for improvement of GCM simulations of the MJO.

Emanuel (1987) and Neelin et al. (1987) proposed that the MJO arises from wind-induced surface heat exchange (WISHE), or wind-evaporation feedback. Sobel et al. (2010) and Maloney et al. (2010) provide further evidence to support the significance of the surface heat flux with regard to the MJO. Although referred to as an oscillation, the MJO is episodic rather than periodic (Salby and Hendon 1994; Hartmann and Hendon 2007). Therefore, rather than being an instability mechanism, 
it is possible that it is irregularly forced. Motivated by Gill (1980), Chao (1987) interpreted the MJO as an atmospheric response to a large-scale, eastward-moving heat source. Wang and Rui (1990) suggested that frictional moisture convergence couples the equatorial Kelvin and Rossby waves through organized convective heating and selects a slowly eastward-moving, planetary-scale unstable mode. The boundary layer convergence leading the convective center is the key to this theory, and it has been confirmed by observations (Wang 2005; Zhang 2005). Raymond (2001) emphasizes the cloud-radiative feedback mechanism, which points to cloud parameterization for possible improvements of the GCMs.

Majda and Biello (2004) and Biello and Majda (2005) focus on the observed multiscale nature of the MJO. In their model, fluxes of kinetic energy and heat arise at synoptic scales and form a planetary-scale convective envelope that forces the MJO. Majda and Stechmann (2009) show how planetary-scale moisture and heating anomalies interact with synoptic-scale wave activity, and they derive a frequency that matches that of the MJO when realistic values of parameters are used.

Also focusing on the multiscale structure, Zou and Cho (2000) investigated the idea that the MJO is a wave packet. They reduced the problem to the one-dimensional nonlinear Schrödinger equation and concluded that the MJO is the result of eastward propagation of a group of mixed Rossby-gravity (MRG) waves or Rossby waves. They did not provide an observational test of this hypothesis.

Wheeler and Kiladis (1999, hereafter WK99) pointed out that the MRG group velocity is $\sim 5 \mathrm{~m} \mathrm{~s}^{-1}$. Straub and Kiladis (2003) pursued the wave packet idea further and noted that the group velocity of MRG waves matches the speed of the MJO. They performed a statistical test using outgoing longwave radiation (OLR) data and concluded that the MRG variance is correlated with the MJO signal. The correlation is not large, although it is statistically significant, and the paper does not figure prominently in later review articles (e.g., Kiladis et al. 2009). Solodoch et al. (2011) have suggested that equatorial winds due to MRG wave packets (also known as Yanai waves) lead to convective heating via a nonlinear WISHE feedback. In their model, this heating forces Kelvin waves with characteristics similar to those of the observed MJO.

Figure 1 shows brightness temperature over the Indian and western Pacific Oceans for a typical MJO event. Low brightness temperature represents deep convection. The convective center of the MJO propagates to the east at a speed of $\sim 5 \mathrm{~m} \mathrm{~s}^{-1}$ and lasts from day 1 to day 30 . Besides the eastward-moving MJO envelope, the $11 \mathrm{~m} \mathrm{~s}^{-1}$ westward-propagating fine structure is prominent as

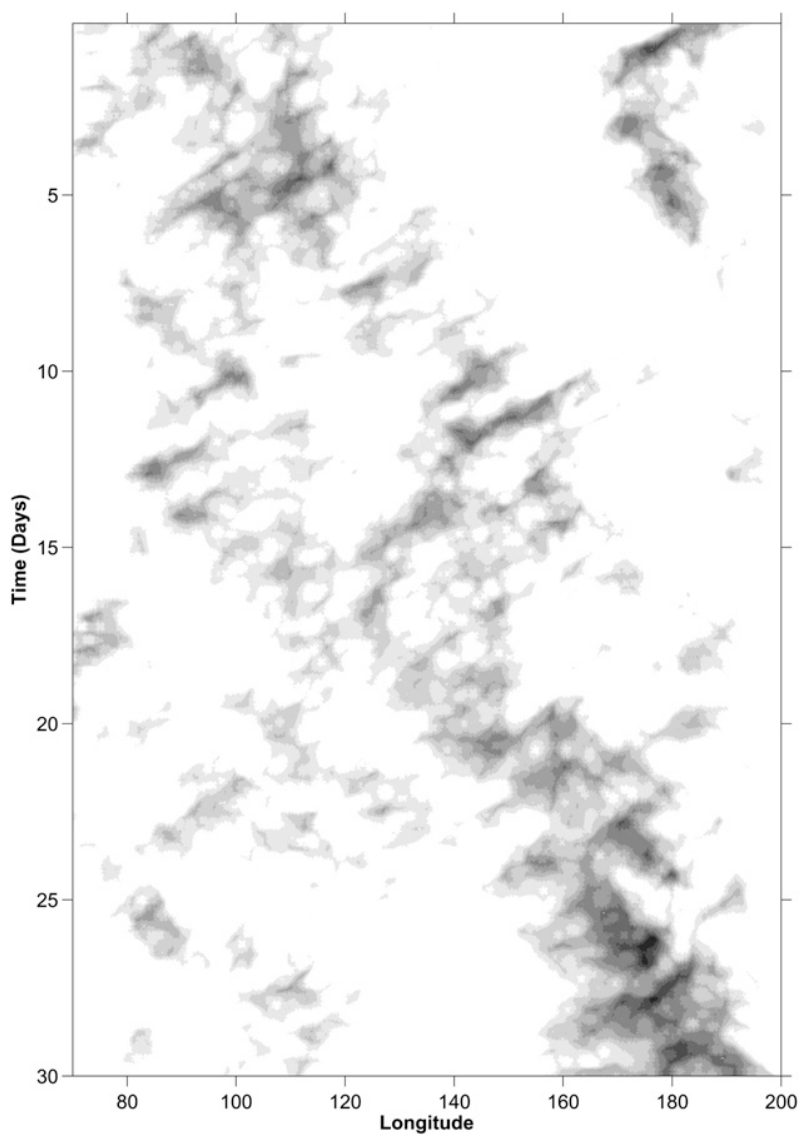

FIG. 1. Time-longitude diagrams of the brightness temperature over $0^{\circ}-10^{\circ} \mathrm{S}$ for $2-31$ Dec 1992 , during which time an MJO event propagated through the eastern Indian and western Pacific Oceans (the same time interval as in Fig. 11 of Chen et al. 1996). Dark represents low brightness temperature, which means high clouds; white represents high brightness temperature.

well. The apparent eastward propagation of the largescale convective center of the MJO is due to consecutive development of new convective systems, each to the east of the previous one. This behavior resembles that of a dispersive wave in which the phase speed is westward and the group velocity is eastward. In this study, we will further test the hypothesis that the MJO is a packet of MRG waves and that it propagates with the MRG group velocity, which is eastward at $5 \mathrm{~m} \mathrm{~s}^{-1}$. The MRG wave packets share important features of the MJO, including its large- and small-scale space-time structure and its propagation behavior, but this hypothesis does not fully pass the observational test that we describe below.

In section 2 we carry out numerical simulations with an idealized three-dimensional GCM. We interpret the GCM results using the linear equatorial waves derived by Matsuno (1966) from the shallow water equations on an equatorial beta plane. These waves are classified into different wave types including Kelvin, equatorial Rossby 


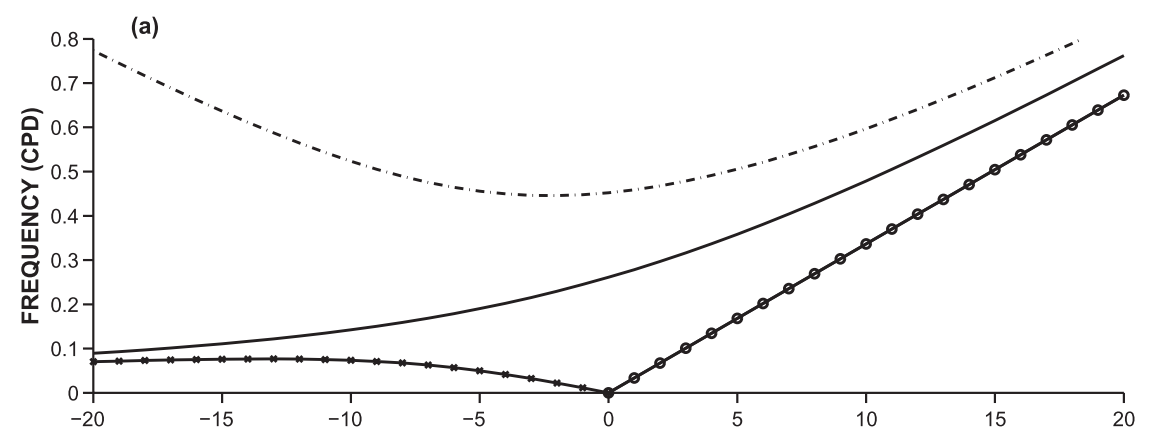

(b)

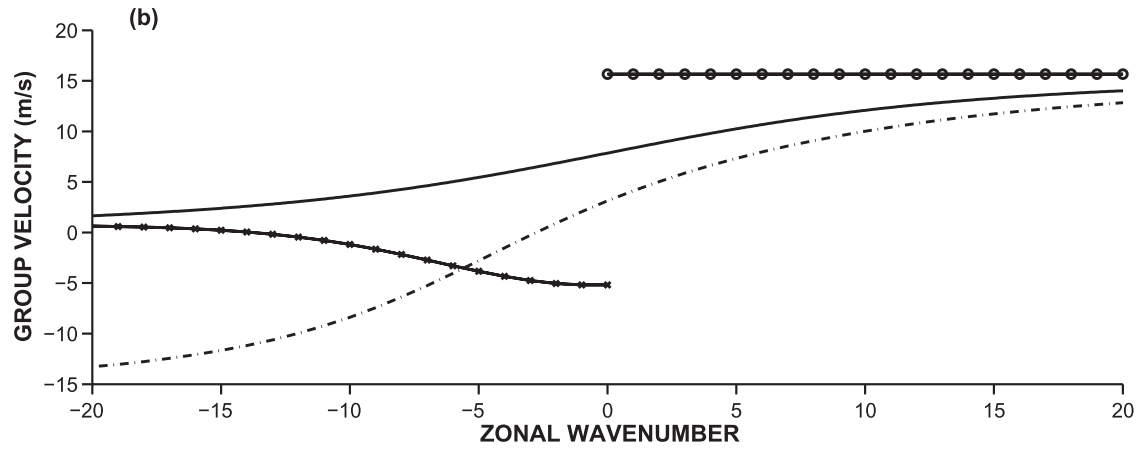

FIG. 2. (a) WIG and EIG waves (dot-dashed), MRG waves (solid), equatorial Rossby (ER) waves (crosses), and Kelvin waves (open circles). (b) The corresponding group velocities. All the curves are for equivalent depth $=25 \mathrm{~m}$. The Kelvin wave phase speed and group velocity are both equal to $c=15.7 \mathrm{~m} \mathrm{~s}^{-1}$.

(ER), westward and eastward inertio-gravity (WIG and EIG), and MRG waves. In section 3 we use the filtering technique developed by WK99 to analyze the OLR observations from the National Oceanic and Atmospheric Administration (NOAA), focusing on the relation between MRG waves and the MJO. In section 4 we discuss the results of sections 2 and 3 , and we present our conclusions and ideas for future work.

\section{Theory and modeling}

Matsuno (1966) theory applies to small-amplitude surface waves in two dimensions on the equator of a rotating planet. The assumption of a basic state of rest is implicit. The theory can be applied to small-amplitude waves in three dimensions by treating each vertical normal mode separately. There are two parameters in the Matsuno theory: the planetary vorticity gradient $\beta$ and the gravity wave $c$. Each normal mode has a different value of $c$. The value of $c$ depends on the mode number, the scale height of the atmosphere, whether it is weakly or strongly stratified, and whether it is moist or dry. There are theories on how to relate the dry dynamics to the moist dynamics, although exactly why moist waves have the same dispersion pattern as the dry waves, but with different values of $c$, remains a mystery (Kiladis et al. 2009). WK99 have shown that there is a particular range of $c$ values for which a close correspondence exists between wavenumber-frequency spectral peaks of the OLR data and the dispersion relations of the linear equatorial waves. The $c$ values are usually expressed in terms of equivalent depth $h=c^{2} / g$, where $g$ is the gravitational acceleration.

Figure 2a shows equatorial wave dispersion curves for $h=25 \mathrm{~m}\left(c=15.7 \mathrm{~m} \mathrm{~s}^{-1}\right)$, which is a typical value from the WK99 analysis. For a point on one of the curves, the slope of the line to the origin gives the phase speed, and the slope of the tangent to the curve gives the group velocity. Positive slope (upward to the right) indicates eastward propagation. Figure $2 \mathrm{~b}$ shows the group velocities of equatorial waves with the same equivalent depth as Fig. 2a, all as functions of their longitudinal wavelengths. The Kelvin wave phase speed and group velocity are both equal to $c$ and are too fast to match the MJO. The MRG group velocity is consistent with the MJO propagation speed within a wide zonal wavenumber range. The ER, WIG, and EIG waves have positive group velocity for part of the zonal wavenumber range, but the ER group velocity seems too slow to match the MJO propagation speed. Of all these waves, the MRG group velocity has the best match to the MJO.

In our first test of the wave packet hypothesis, we use an idealized GCM to simulate the equatorial waves. The GCM is based on the spectral dynamical core of the 
Geophysical Fluid Dynamics Laboratory's (GFDL's) Flexible Modeling System. The horizontal resolution is T42 and there are 26 unevenly spaced sigma levels. This is a dry model, but we have reduced the effective static stability by increasing the specific heat. With this change, the first baroclinic mode- the one that spans the troposphere from top to bottom-matches the phase speed $c \approx$ $15.7 \mathrm{~m} \mathrm{~s}^{-1}$ of the observed convectively coupled waves. A more realistic GCM must match the phase speed by correctly simulating the interaction of waves with moist convection. This is an important requirement for any GCM if the interaction with convectively coupled waves turns out to be an important element of the MJO.

The two types of dissipation in our GCM are a linear damping of velocities in the boundary layer (Held and Suarez 1994) and a sponge layer in the stratosphere [Eq. (1)]:

$$
\begin{aligned}
& \frac{\partial \mathbf{v}}{\partial t}=\cdots-k_{\mathbf{v}}(\sigma) \mathbf{v} \\
& k_{\mathbf{v}}=k_{f}\left[\max \left(0, \frac{\sigma_{s}-\sigma}{\sigma_{s}}\right)+\max \left(0, \frac{\sigma-\sigma_{b}}{1-\sigma_{b}}\right)\right] \\
& \sigma_{s}=0.1 ; \quad \sigma_{b}=0.7 \\
& k_{f}=1 \text { day }^{-1}
\end{aligned}
$$

Here, $\mathbf{v}$ is the vector velocity, $t$ is time, and $\sigma$ is $p / p_{\text {surf }}$, where $p_{\text {surf }}$ is the surface pressure; also, $\sigma_{b}$ is the top of the boundary layer and $\sigma_{s}$ is the base of the sponge layer. Temperatures are relaxed to the equilibrium temperature field (Held and Suarez 1994), but the equilibrium temperature is a function of altitude only. Simulations are carried out over an aquaplanet. Each simulation is initiated by a heat source [Eq. (2)] moving at speed $c_{s}\left(c_{s}>0\right.$ is eastward; $c_{s}<0$ is westward); $Q$ represents the heating. Also, $x, y$, and $\sigma$ are zonal, meridional, and vertical coordinates, respectively, and $x_{0}$ and $t_{0}$ are respectively the initial zonal and temporal positions.

$$
\begin{aligned}
Q \sim & Q_{t} Q_{h} Q_{\sigma} ; \\
Q_{t}= & 1-\frac{\left(t-t_{0} / 2\right)^{2}}{\left(t_{0} / 2\right)^{2}}, \quad 0 \leq t \leq t_{0} ; \\
Q_{h}= & y\left[1-\frac{\left(x-x_{0}-c_{s} t\right)^{2}+y^{2}}{r^{2}}\right], \\
& \left(x-x_{0}-c_{s} t\right)^{2}+y^{2} \leq r^{2} ; \\
Q_{\sigma}= & \cos \left(\frac{\pi}{2} \frac{\sigma-\sigma_{0}}{1-\sigma_{0}}\right), \quad \sigma_{s} \leq \sigma \leq 1 .
\end{aligned}
$$

The forcing [Eq. (2)] increases from zero to a maximum and then decreases to zero again during a time interval $t_{0}$. It has an imposed horizontal scale $r \sim 3000 \mathrm{~km}$. The heating profile has its maximum at the middle troposphere $\left(\sigma_{0}=0.55\right)$ and is zero at the ground $(\sigma=1)$ and the base of the stratosphere $\left(\sigma=\sigma_{s}=0.1\right)$. The forcing is near the equator and can be either symmetric or antisymmetric about it.

Examples are shown in Fig. 3. Although these are 3D simulations on a sphere, we interpret the results using the Matsuno (1966) theory of 2D waves trapped at the equator (Fig. 2). Figure 3a shows the waves excited by an antisymmetric forcing that increases from zero to the maximum and decreases to zero again over a 20-day period and moves westward at $9 \mathrm{~m} \mathrm{~s}^{-1}$. The waves whose phase speed matches that of the forcing are resonantly excited-they remain in phase with the forcing-and in Fig. 3a these are the westward-moving MRG waves (Fig. 2). The bandwidth in frequency is inversely proportional to the duration of the forcing. The wave's group velocity is $\sim 4 \mathrm{~m} \mathrm{~s}^{-1}$ to the east. Despite having the same damping rates $\left(1 \mathrm{day}^{-1}\right.$ in the boundary layer and no sponge layer) as those used in idealized climate modeling (Held and Suarez 1994), the MRG wave packet maintains its identity for longer than 30 days. Moreover, the wave packet is a planetary-scale feature. Because the spectrum analysis shows the scales of waves only, the scale of the wave packet cannot be seen on the wavenumberfrequency spectrum. Such time-space structure and propagation speed are the same as for the MJO events. We also experimented with a sponge layer [Eq. (1)]. This is to prevent energy from being reflected back from the upper boundary. With or without the sponge layer, the wave packet still lasts longer than 30 days. Figure $3 \mathrm{~b}$ shows another simulation with the same forcing but without the boundary layer damping. The intense contours maintain longer than 40 days.

The simulation shown in Fig. $3 \mathrm{c}$ is forced with a 10-day storm moving westward at $9 \mathrm{~m} \mathrm{~s}^{-1}$. Because the forcing lasts for a shorter length of time than in the previous simulations, the excited waves are not purely MRG waves. However, the dominant feature is still the MRG wave packet, which moves to the east at $\sim 4 \mathrm{~m} \mathrm{~s}^{-1}$. In Fig. 3d, the waves are excited by a storm moving to the west at $4 \mathrm{~m} \mathrm{~s}^{-1}$, which is slower than the speed in Figs. 3a-c. From Fig. 2a, we can see that if there is a heat source moving to the west at $4 \mathrm{~m} \mathrm{~s}^{-1}$, both ER and MRG waves will be excited. Figure 3d shows the mixture of ER and MRG waves. During days 1-25, there is a dominant MRG wave packet between $120^{\circ}$ and $250^{\circ} \mathrm{E}$, which propagates to the east at $\sim 4.6 \mathrm{~m} \mathrm{~s}^{-1}$. Between day 25 and day 50 , the dominant features are the westward-drifting phase lines with a stationary wave packet. Both the phase speed and the group velocity are small, which suggests ER waves. The weak eastward-propagating wave packet 

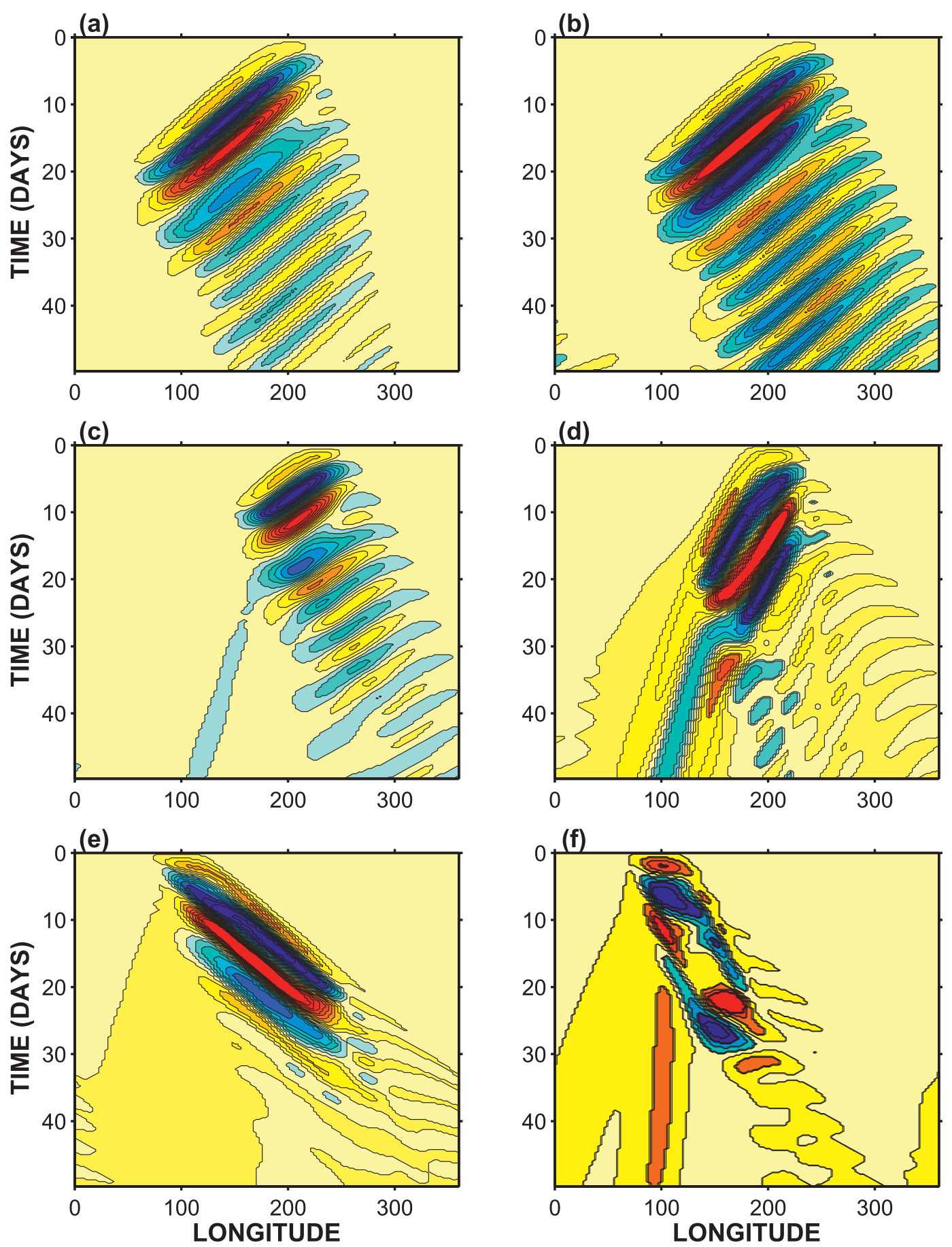

FIG. 3. Time-longitude diagrams of the air temperature anomaly in the GCM at $\sigma \approx 0.5$. Temperature has been averaged from $0^{\circ}$ to $4.2^{\circ} \mathrm{N}$. Blue color indicates a negative temperature anomaly and red, a positive anomaly. (a) Source moves to the west at $9 \mathrm{~m} \mathrm{~s}^{-1}$ and lasts for 20 days; boundary layer damping is 1 day $^{-1}$. (b) As in (a), but there is no boundary layer damping. (c) As in (a), but source lasts for 10 days. (d) As in (a), but source moves at $4 \mathrm{~m} \mathrm{~s}^{-1}$. (e) As in (a), but source moves to the east at $9 \mathrm{~m} \mathrm{~s}^{-1}$. (f) As in (e), but the source moves to the east at $4 \mathrm{~m} \mathrm{~s}^{-1}$ and there is no boundary layer damping. 

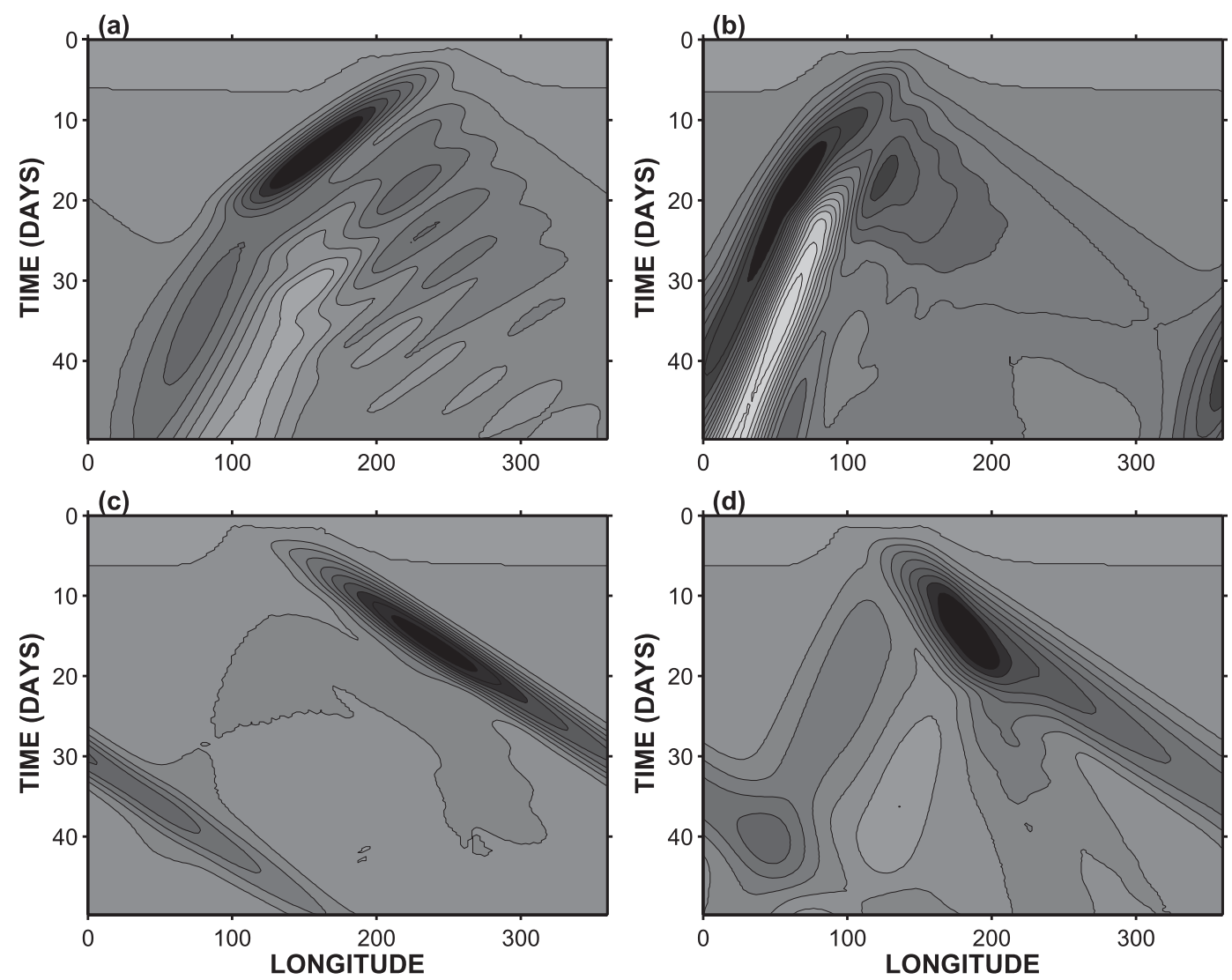

FIG. 4. Time-longitude diagram of the air temperature anomaly in the GCM at $\sigma \approx 0.5$. Temperature has been averaged from $4.2^{\circ}$ to $9.8^{\circ} \mathrm{N}$. Anomaly increases with the darkness of the color. The source is a dipole-a positive heating anomaly to the north and a negative anomaly to the south, which is the same as in Fig. 3a, but the zero line has been displaced north from the equator to latitude $5.6^{\circ}$. (a) Source moving to the west at $\sim 9 \mathrm{~m} \mathrm{~s}^{-1}$. (b) Source moving to the west at $\sim 4 \mathrm{~m} \mathrm{~s}^{-1}$. (c) Source moving to the east at $\sim 9 \mathrm{~m} \mathrm{~s}^{-1}$. (d) Source moving to the east at $\sim 4 \mathrm{~m} \mathrm{~s}^{-1}$.

could be an MRG wave packet. These figures tell us that westward MRG waves can form wave packets that mimic the features of the MJO.

Figure 3e shows a wave packet excited by the same forcing as that in Fig. 3a but moving to the east at $9 \mathrm{~m} \mathrm{~s}^{-1}$. From Fig. 2a, we can see that an eastward $9 \mathrm{~m} \mathrm{~s}^{-1}$ heating source cannot resonantly excite any of the eastward waves in the Matsuno diagram. Thus, Fig. 3e shows a variety of linear responses, one of which might be an MRG wave. Figure $3 f$ shows a simulation with an eastward forcing at $4 \mathrm{~m} \mathrm{~s}^{-1}$ over a 20 -day period. As discussed above, the slow-moving source will not resonantly excite any waves in the Matsuno diagram. Thus, the response in Fig. 3f does not have the typical wave structure.

Figure 3 tells us that westward-moving storms can excite MRG wave packets moving eastward at $\sim 5 \mathrm{~m} \mathrm{~s}^{-1}$. Even eastward-moving storms can excite MRG wave packets, as in Fig. 3e. The packet speed is relatively insensitive to the speed of the storm. The packets last longer than the storms, but the storms determine the interval between events. We have varied the meridional extent of the forcing, including forcings with an extent of $\sim 1000 \mathrm{~km}$, which is about the equatorial waveguide (i.e., one Rossby deformation radius). The results are similar to those of Fig. 3. The MRG wave packets are not sensitive to the meridional extent of the forcing. If the MJO is composed of MRG waves, it could be an atmospheric response to an equatorial or extratropical forcing. This idea is consistent with the view that the MJO is episodic, with an irregular time interval between events, rather than a periodic oscillation (Salby and Hendon 1994; Hartmann and Hendon 2007).

The forcings in Fig. 4 resemble those in Fig. 3a but are displaced northward by $5.6^{\circ}$. That is, the coordinate $y$ in Eq. (2) is replaced by $y-y_{1}$, where $y_{1}$ is the $5.6^{\circ}$ latitude line. As in Fig. 3a, the forcing of Fig. 4a moves to the west at $\sim 9 \mathrm{~m} \mathrm{~s}^{-1}$. Since the forcing is neither symmetric nor antisymmetric about the equator, one would expect a linear combination of different meridional equatorial waves. There is a nondispersive wave moving 

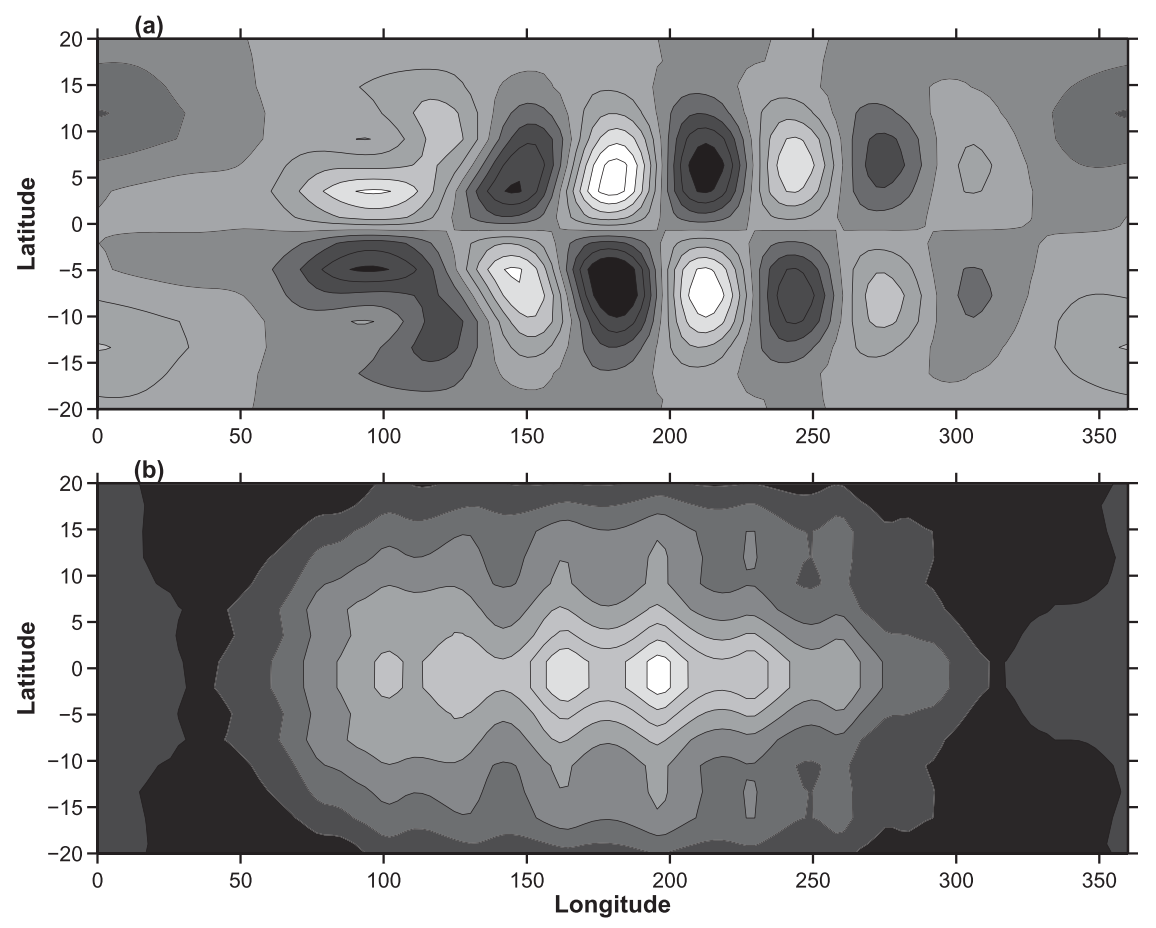

FIG. 5. (a) Map view of the MRG divergence field at $\sim 160 \mathrm{mb}$. White represents positive divergence and black, negative divergence. Contour intervals are equal. (b) Map view of the rectified MRG divergence field. The white is high, the black is low, and the gray is intermediate.

to the west at $\sim 3.3 \mathrm{~m} \mathrm{~s}^{-1}$ from days 25 to 50 . It could be a low-wavenumber ER wave. There is also an eastwardpropagating wave packet with a group velocity of $\sim 7.5 \mathrm{~m} \mathrm{~s}^{-1}$. The phase lines of the packet move to the west at $\sim 10 \mathrm{~m} \mathrm{~s}^{-1}$. This wave packet could be composed of MRG waves. Although the forcing is not strictly antisymmetric about the equator, an MRG wave packet has been excited. The forcing in Fig. $4 \mathrm{~b}$ moves to the west at $\sim 4 \mathrm{~m} \mathrm{~s}^{-1}$. There is a strong nondispersive wave moving to the west at $\sim 2.8 \mathrm{~m} \mathrm{~s}^{-1}$, which could be a low-wavenumber ER wave. Another strong signal is a wave packet moving eastward at $\sim 11.6 \mathrm{~m} \mathrm{~s}^{-1}$. Within the wave packet, there are westward-moving phase lines, which is a signature of MRG waves. However, it is faster than the MJO propagation speed. The forcing in Fig. $4 \mathrm{c}$ moves eastward at $\sim 9 \mathrm{~m} \mathrm{~s}^{-1}$. The most dominant feature is the nondispersive wave, which propagates at $\sim 11.1 \mathrm{~m} \mathrm{~s}^{-1}$. Considering this propagation speed and the nondispersive feature, this could be a Kelvin wave. The forcing in Fig. $4 \mathrm{~d}$ moves eastward at $\sim 4 \mathrm{~m} \mathrm{~s}^{-1}$. The forcing excites both westward- and eastward-moving structures. The structure moving westward at $\sim 3.8 \mathrm{~m} \mathrm{~s}^{-1}$ could be the ER wave. The nondispersive structure moving eastward at $10.6 \mathrm{~m} \mathrm{~s}^{-1}$ could be the Kelvin wave. There is another eastward-moving anomaly, which is weaker and moves at $\sim 2 \mathrm{~m} \mathrm{~s}^{-1}$. Simulations in Figs. $4 \mathrm{a}-\mathrm{d}$ do not excite pure
MRG waves. In contrast, they excite mixtures of equatorial waves, since the forcing is neither symmetric nor antisymmetric about the equator and such forcing corresponds to a mixture of different meridional modes.

Certain aspects of this hypothesis need further discussion. First, the MRG waves (Fig. 5a) are antisymmetric about the equator, but the MJO and the MRG wave packets are symmetric. To get the wave packet, we square the wave amplitude to get the variance and then smooth the result over several spatial wavelengths. The packets are the rectified MRG waves (Fig. 5b). When we rectify the MRG waves, we use a two-dimensional boxcar average over $\sim 20^{\circ}$ in latitude and longitude. The hypothesis is that clouds will spread in the upper troposphere and form the rectified MRG waves. The rectified MRG waves are symmetric; they have a maximum at the equator and look strong only in the active MRG wave regions-where the original MRG wave signal varies periodically from a large negative anomaly to a large positive anomaly. The packets - the large-scale, rectified MRG waves-have a different structure than the individual crests and troughs. It is the rectified wave (i.e., the wave packet) that has some of the features of the MJO.

Second, the model does not require a reduced vertical wavelength to get a slow propagation speed. In fact, the vertical structure of the waves in these simulations is 


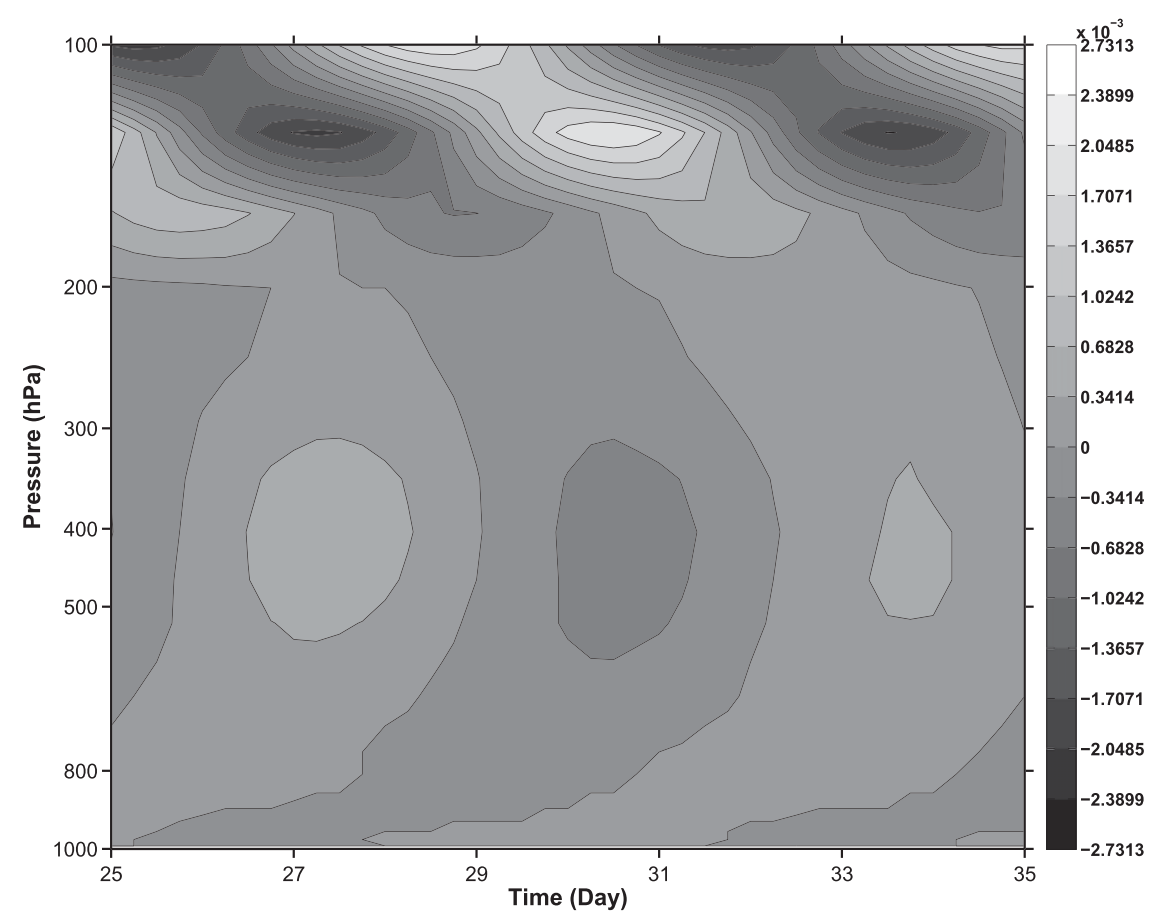

FIG. 6. Pressure-time cross section of the temperature anomaly at $5^{\circ} \mathrm{N}, 220^{\circ} \mathrm{E}$.

similar to the observations. Figure 6 shows the timepressure cross section of the temperature anomalies of the simulated MRG waves. The first baroclinic mode is dominant-the temperature anomaly reaches the maximum in the midtroposphere and decreases both toward the ground and toward the tropopause, but the second baroclinic mode is present. Since time increases to the right, the downward slope in the upper atmosphere indicates downward phase propagation or upward energy propagation, which is consistent with energy dissipation in the sponge layer. The opposite slope in the lower atmosphere is consistent with energy dissipation in the boundary layer. As a result, the temperature maximum in the boundary layer occurs at the same time as the temperature minimum at $400 \mathrm{hPa}$ and vice versa, indicating the presence of the second baroclinic mode. The direction of slope in the upper and lower atmosphere agrees with observation (Kiladis et al. 2009), but the second baroclinic mode is stronger in the observations than in Fig. 6.

Third, De Leon et al. (2010) showed that the MRG wave does not exist on a sphere if there are boundaries at midlatitudes; instead, the first ER mode and the first westward inertio-gravity wave mode are separated by the anti-Kelvin wave for all values of the zonal wavenumber (the anti-Kelvin wave is a westward-propagating edge wave with maximum amplitude at the midlatitude boundary). However, our 3D simulation is carried out on a sphere without midlatitude boundaries, and the MRG waves still behave as predicted in the Matsuno theory. For these equivalent depths, the MRG waves are trapped within $\sim 1000 \mathrm{~km}$ of the equator, which is small compared to the pole-to-equator distance. As a result, the equatorial beta plane without boundaries is a good approximation.

\section{Data analysis}

The other test of the wave packet hypothesis uses once-daily estimates of outgoing longwave radiation from the NOAA polar-orbiting satellites (Liebmann and Smith 1996) extending from June 1974 to July 2009. Low brightness temperatures are taken to be areas of deep tropical convection and enhanced precipitation (WK99). The data from each scanning swath of the satellite are archived on a $2.5^{\circ}$ grid, allowing representation of highwavenumber features.

The method used for this part of the study is spacetime spectral analysis as pioneered by WK99. Figures 7a and $7 \mathrm{~b}$ show contours of the logarithm of the power in the antisymmetric and symmetric (about the equator) components of the OLR. Superimposed upon these two plots are the dispersion curves for linear equatorial waves with even and odd meridional mode number, for various equivalent depths and for a zero wind basic state. The equivalent depths of the two MRG dispersion 

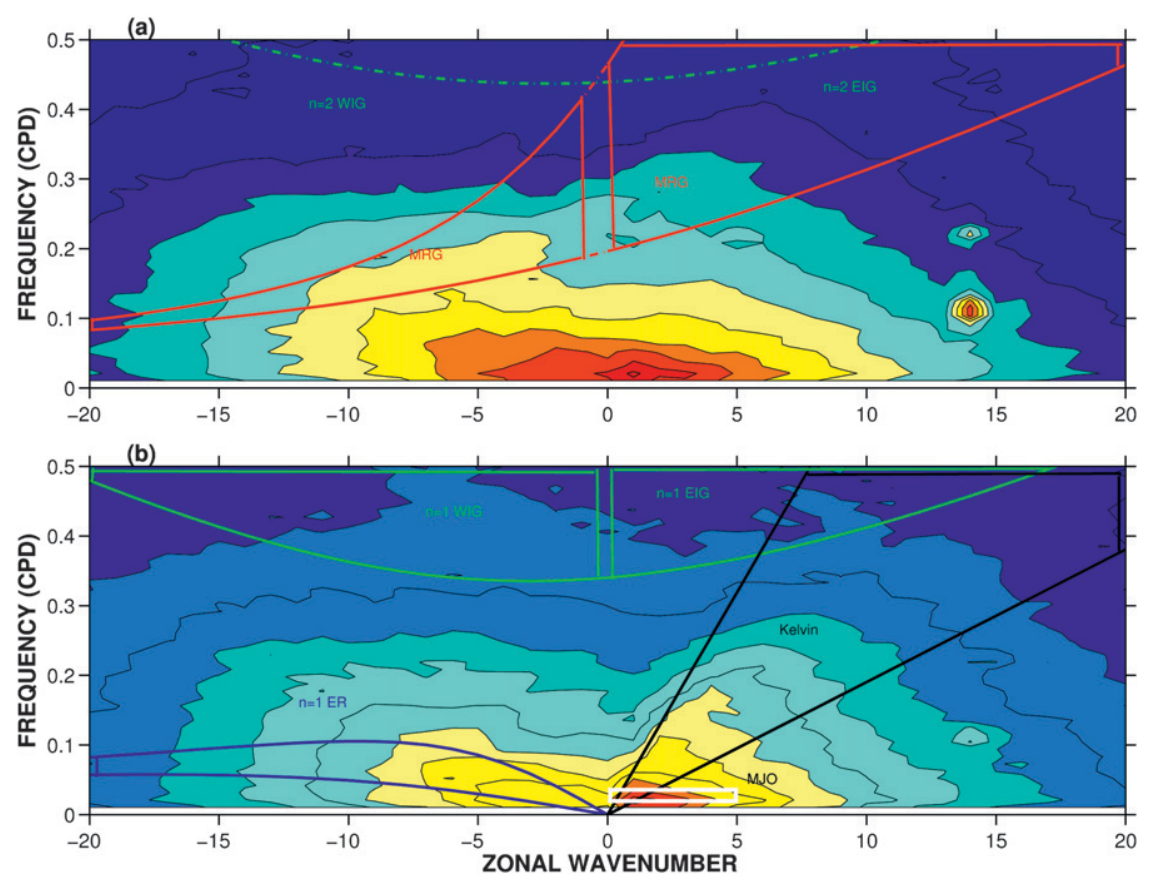

FIG. 7. (a) Zonal wavenumber-frequency power spectra of the antisymmetric component of OLR, calculated for the entire period of record from 1974 to 2009. The superimposed green line is the inertio-gravity wave; the red lines are the MRG waves with equivalent depths of 8 and $250 \mathrm{~m}$. (b) As in (a), but for the symmetric component. The green curve is the WIG and EIG wave; blue is the ER wave, and black is the Kelvin wave with equivalent depths of 8 and $90 \mathrm{~m}$. Although not predicted by linear wave theory, the MJO is the power that is concentrated in the white box to the right of center and close to the horizontal axis. For all components, the power has been summed over $10^{\circ} \mathrm{S}-10^{\circ} \mathrm{N}$. Solid boxes represent regions used in the wavenumberfrequency filtering.

curves (the solid and dashed red lines curving upward to the right) in Fig. 6a are $8 \mathrm{~m}$ and $250 \mathrm{~m}$, respectively. The other dispersion curves (Kelvin = black, $\mathrm{ER}=$ blue) in Figs. $7 \mathrm{a}$ and $7 \mathrm{~b}$ have equivalent depths of $8 \mathrm{~m}$ and $90 \mathrm{~m}$, respectively. The equatorial waves are most active within these equivalent depth ranges (WK99). Most of the power is located at the low-frequency and lowwavenumber region. In this study, the MJO spectral power is defined in the white box to the right of the origin close to the horizontal axis. This is the power within the wavenumber range from 1 to 5 and the frequency domain from 1/96 to $1 / 40$ cycles per day; it appears in both Figs. 7a and 7b. Although the MJO signal is the strongest signal in the wavenumber-frequency diagram, no linear equatorial wave in the Matsuno theory matches the MJO signal. Following WK99, we filter the signal by looking only at the Fourier coefficients in each of the boxes outlined in Fig. 7.

In Fig. 8 we show a specially selected example that illustrates our method: a time-longitude section of a 40-day OLR field (Fig. 8a) at its full $2.5^{\circ}$ longitude and once-daily time resolution. Not all 40 -day sections are this illustrative. The OLR has been averaged over $10^{\circ} \mathrm{S}-$ $5^{\circ} \mathrm{N}$, which is the mean latitudinal position of Indian Ocean MJO events (Waliser et al. 2009). There are three longitudinal centers of low OLR, which correspond to the three convectively active regions. Over the Indian and western Pacific Oceans, besides the slow eastwardpropagating convection systems, there are smaller-scale disturbances moving to the west. These small disturbances could be the MRG waves (WK99). We first examine the convective signals that can be associated with the MJO. Figure $8 \mathrm{~b}$ shows the same time-longitude section as Fig. 8a, but only for the Fourier coefficients in the MJO box. The negative OLR anomaly represents deep convection and therefore the active phase of the MJO. We see that the MJO involves slow progression $\left(\sim 5 \mathrm{~m} \mathrm{~s}^{-1}\right)$ of convective activity from the Indian Ocean to the central Pacific, and it is dominated by zonal wavenumbers 2 and 3 , which is a typical horizontal scale for the OLR signature of the MJO. In Fig. 8c, the MRG wave has a phase speed that varies between -10 and $-15 \mathrm{~m} \mathrm{~s}^{-1}$ and a positive group velocity of $\sim 6 \mathrm{~m} \mathrm{~s}^{-1}$. Between day 5 and day 25, when the MJO is the strongest, 

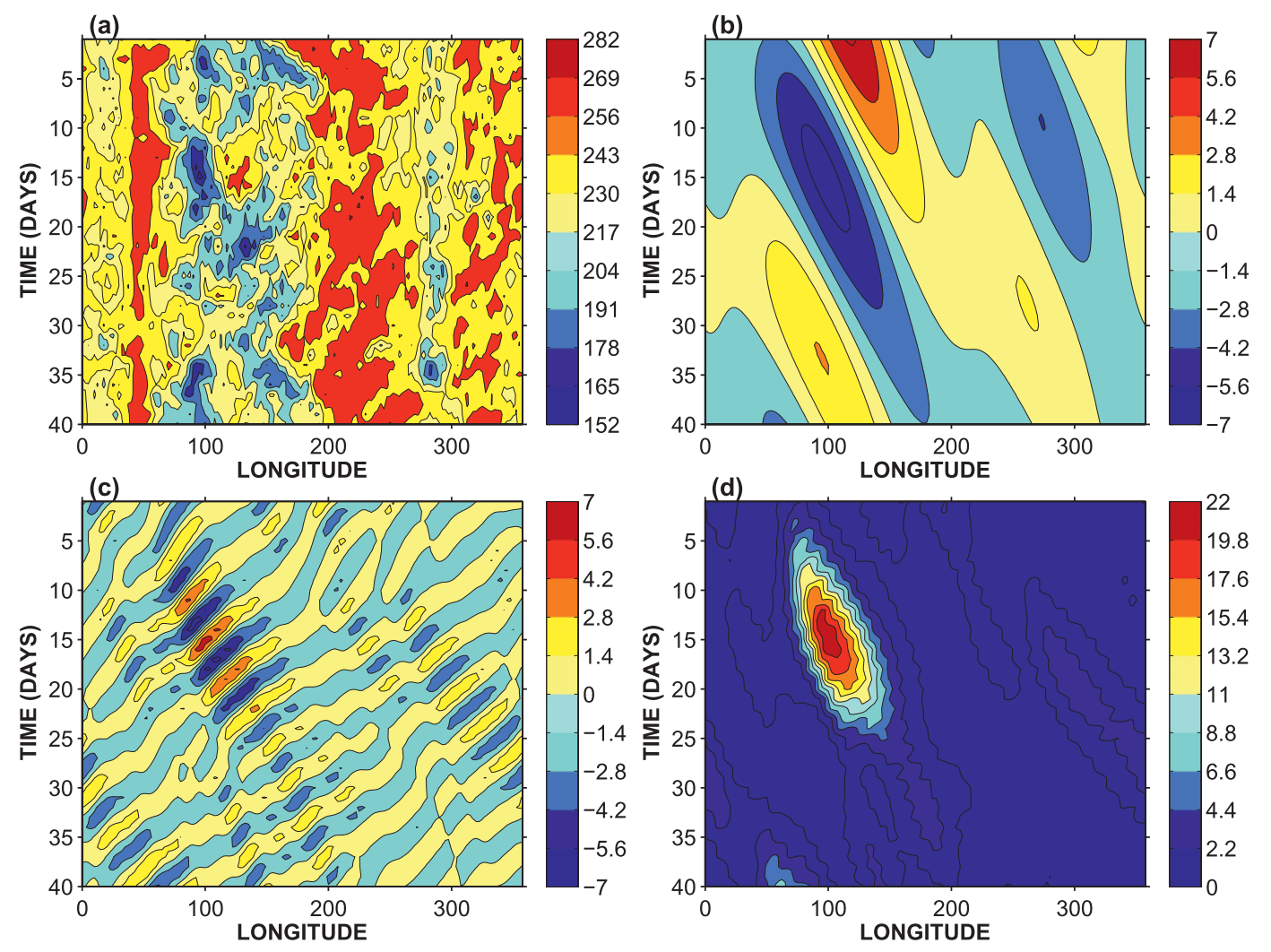

FIG. 8. (a) Time-longitude diagrams of OLR $\left(\mathrm{W} \mathrm{m}^{-2}\right)$ averaged for the latitudes from $10^{\circ} \mathrm{S}$ to $5^{\circ} \mathrm{N}$. The record extends from 11 Jul to 19 Aug 1985. (b) Time-longitude section of OLR anomalies for the MJO-filtered band for the same 40-day period as in (a). (c) The MRG-filtered band for the same 40-day period. (d) The rectified MRG waves for the same 40-day period.

there is an intense MRG wave packet traveling eastward from $70^{\circ}$ to $150^{\circ} \mathrm{E}$. Figure $8 \mathrm{~d}$ shows the rectified MRG wave, which captures the major characteristics of the MRG packets. Comparing Figs. $8 \mathrm{~b}$ and $8 \mathrm{~d}$, we see that the MRG packet matches the MJO event. They have similar propagation speeds, and they occur at the same place during the same time. In addition, the MRG phase speed is similar to that of the small disturbances propagating within the MJO (shown in the raw OLR field; Fig. 8a).

Figure 9 shows the results of an analysis that uses the complete 1974-2009 OLR data to calculate the joint probability distribution (JPD) of the MJO and the rectified westward and eastward MRG, Kelvin, EIG, and ER waves. From the raw data, we can filter the MJO signal and then project back into the longitude and time domain, as we did in Fig. 8b. The figure is for the Indian Ocean MJO, which is defined as the MJO anomaly within the Indian Ocean longitude band, $75^{\circ}-100^{\circ} \mathrm{E}$. The common feature of Fig. 9 is that the largest probability density is near the origin - at low tropical wave activity (rectified waves of each type) and MJO $=0 \mathrm{~W} \mathrm{~m}^{-2}$. The JPD decreases when the tropical wave activity and the absolute value of the MJO anomaly go up. Figures 9a and $9 b$ show the JPD of the westward and eastward MRG waves with the MJO. Both distributions are tilted. That is, when the rectified MRG wave activity is high, there is more likely to be an active MJO phase-a negative MJO signal. The correlation coefficients between westward and eastward MRG waves and the MJO are -0.08 and -0.21 , respectively. The correlation coefficients between the EIG, Kelvin, ER, and WIG waves and the MJO (Figs. 9c-f) are $-0.11,-0.001,-0.04$, and -0.11 , respectively. To test whether these correlations are significant, one needs an estimate of the degrees of freedom (DOF). By analogy with coin flips, if there are $N$ tails in an average experiment, then there are $2 N$ flips of the coin, or $2 N$ DOF. Our statistical test uses $35 \mathrm{yr}$ of data, and the average year has nine MJO events. Within one MJO event, there is one active and one inactive phase. Accordingly, the DOF is $35 \times 9 \times 2=630$. With this DOF, no significant correlation exists between the Kelvin and ER waves and the MJO. However, there is a statistically significant relation between the MJO and 

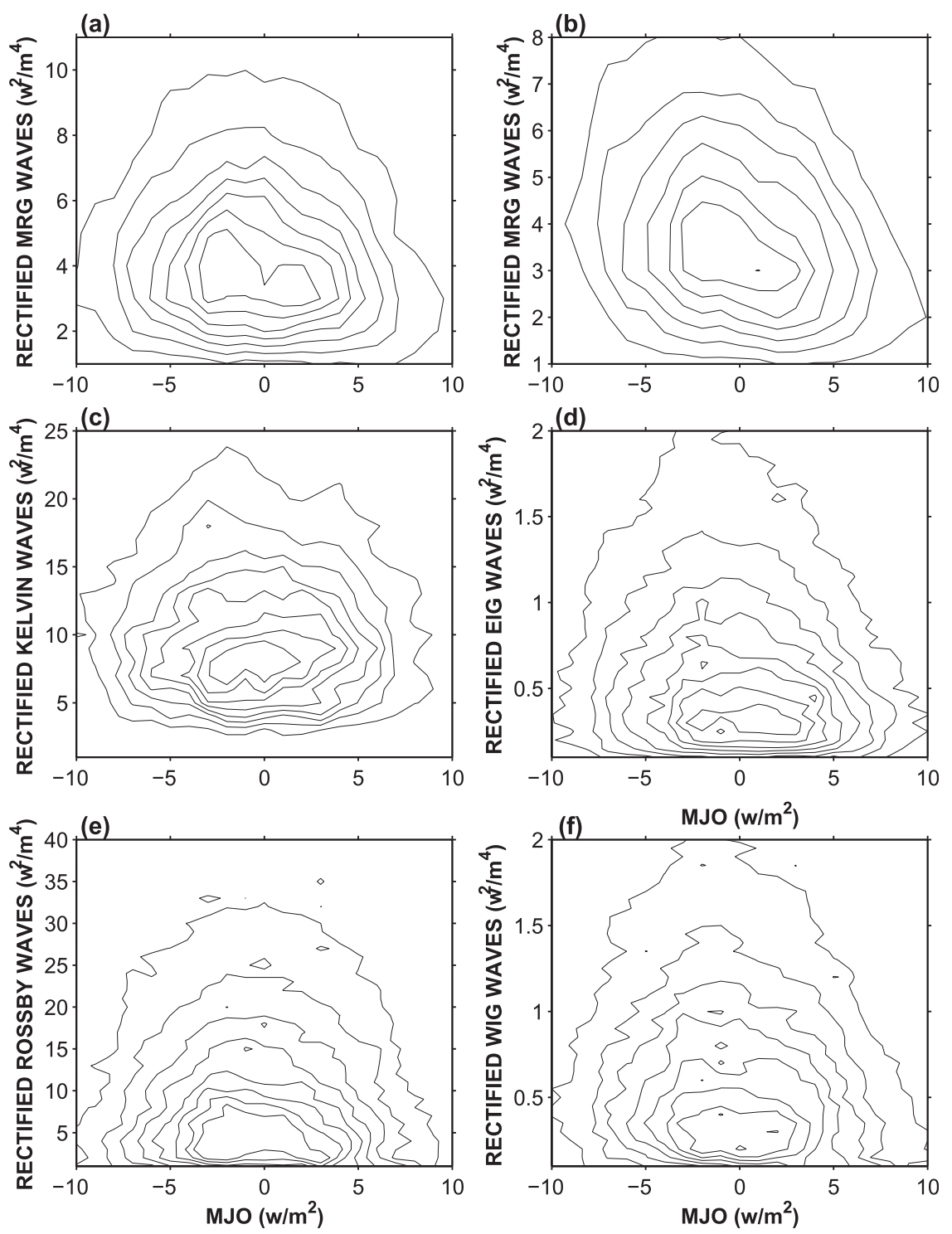

FIG. 9. JPD of the MJO with (a) the rectified westward MRG waves, (b) the rectified eastward MRG waves, (c) the rectified Kelvin waves, (d) the rectified EIG waves, (e) the rectified ER waves, and (f) the rectified WIG waves. We filter using the Fourier coefficients within the boxes shown in Fig. 7. These coefficients were computed from the full global dataset. After inverting the filtered coefficients to a time-longitude plot, we construct the JPD from the Indian Ocean section, $10^{\circ} \mathrm{S}-5^{\circ} \mathrm{N}, 75^{\circ}-100^{\circ} \mathrm{E}$. The contour intervals are the same for each figure, and the maximum and minimum values are also the same. The downward tilt to the right in (a) and (b) is evidence that the rectified MRG waves are correlated with low OLR (increased convective activity) in the MJO frequency band.

both the westward and eastward MRG waves at the $95 \%$ significance level. Also, both EIG and WIG waves are correlated with the MJO signal at the $95 \%$ significance level.

Figure 10 shows the results of another statistical analysis, which uses just the November-April OLR data and covers $75^{\circ}-185^{\circ} \mathrm{E}$. The distributions in Figs. 10c-f are not obviously tilted. Only the JPDs between the MJO and the rectified MRG waves (Figs. 10a,b) are tilted, but the correlation coefficients are only -0.07 and -0.1 . The absolute values of correlation coefficients of other JPDs are even smaller. Compared to the analysis in Fig. 9, this analysis uses a longitude range that is larger by a factor of 4.4 and a temporal range that is smaller by a factor of 2. So the DOF is approximately 1386 . With this DOF, there is a significant correlation only between the MJO 

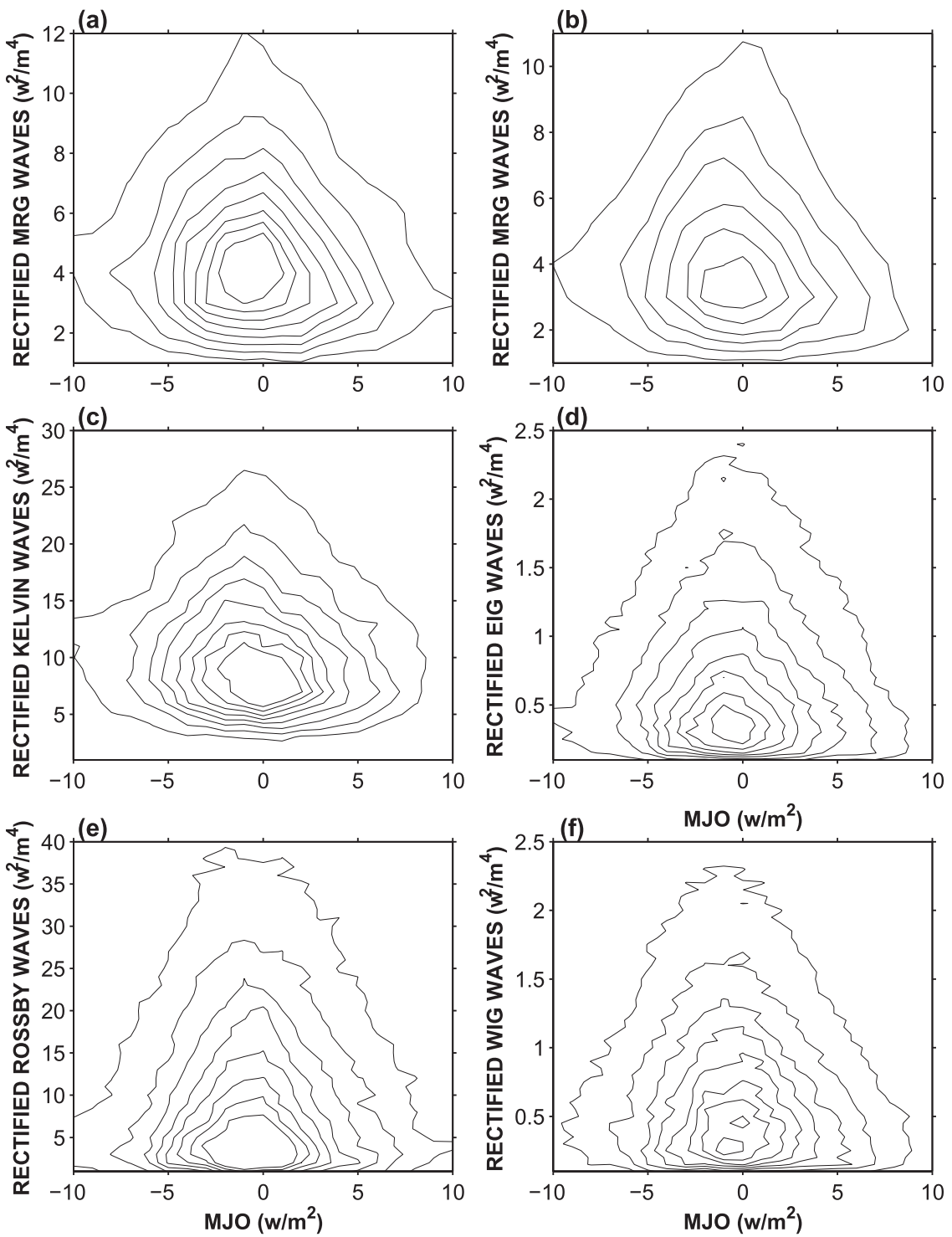

FIG. 10. As in Fig. 9, but these coefficients were computed for just the winter season (November-April) and for $75^{\circ}-185^{\circ} \mathrm{E}$.

and the MRG waves at the $95 \%$ significance level. No significant correlation exists among the IG, Kelvin, and ER waves and the MJO.

The above statistical analysis has been carried out within one Rossby deformation radius of the equator. Therefore, the wave signals are mainly equatorial waves. We did not find significant correlation between the MJO and ER waves. This does not rule out the possibility that the MJO is initiated by subtropical Rossby waves (Hsu et al. 1990) or that its propagation is associated with subtropical Rossby waves (Matthews et al. 1996) or that the midlatitude exerts an influence on the tropics on intraseasonal time scales (Liebmann and Hartmann 1984).

\section{Discussion and conclusions}

We have tested the hypothesis that the MJO is an MRG wave packet propagating with the MRG wave group velocity. The 3D numerical simulation indicates how the MRG wave packet could be forced, and it has some common features with the MJO, including the observed horizontal scale, local duration, and propagation speed. The numerical results suggest that the MJO could be an atmospheric response to a westwardor eastward-moving perturbation. However, when the forcing is not strictly antisymmetric, the MRG wave packet is not the dominant feature of the atmospheric response. 
We are using a dry GCM. It will not simulate the relative arrangement of moisture and convection. With small-amplitude forcing, it is a linear model. As a result, we cannot get all the MJO features, such as the horizontal wind structure and divergence field. This is because the divergence and vertical velocities of the MRG waves average out to zero on the scale of the wave packet (i.e., on the scale of the MJO). Nonlinear effects could alter this. For instance, if updrafts were stronger than downdrafts, one would have net low-level convergence on the scale of the wave packet. Similarly, if condensation on updrafts outweighs evaporation on downdrafts, one would have net heating on the scale of the wave packet. In these cases the response would be similar to the model result of Gill (1980). It is possible that by adding a convection scheme to the GCM a more realistic MJO would be simulated, in that it would be covered by a cloud top, would have a baroclinic wind field, and would be subject to weather noise from higher latitudes.

We have carried out two analyses with the NOAA OLR dataset. The first analysis is for the Indian Ocean MJO. We have found that there is a significant correlation between the MJO and most of the equatorial waves, except the ER and Kelvin waves. The second analysis is for the MJO from November to April. There is a significant correlation only between the MJO and the MRG waves. There are two caveats. First, correlations do not indicate causality, which means it is possible that the MJO is a separate entity that simply modulates the MRG wave (Aiyyer and Molinari 2003) and other correlated waves. Second, correlation analysis is a search for linear relationships, and there is no guarantee of a linear relationship between the rectified waves and the MJO signal. Nevertheless, the main conclusion is that the correlation coefficient is small, which suggests that the MRG waves explain only a small fraction of the MJO variance. The OLR data provide little support for the idea that the MJO propagation speed is set by the MRG wave group velocity. In addition, WK99 pointed out that the strongest OLR variance of the MRG band is near the date line, with a weak variance in the Indian Ocean, which further weakens this hypothesis. Nevertheless, it is still possible that other datasets would reveal a larger correlation between eastward-propagating wave packets and the MJO. Both using a moist GCM to simulate the MRG wave packets and doing a similar test with other more recent datasets would be worthwhile activities for the future work.

Acknowledgments. We thank Dr. Duane Waliser for useful comments and suggestions. This research was supported by the Geological and Planetary Sciences Davidow Fund of the California Institute of Technology.

\section{REFERENCES}

Aiyyer, A. R., and J. Molinari, 2003: Evolution of mixed Rossbygravity waves in idealized MJO environments. J. Atmos. Sci., 60, 2837-2855.

Biello, J., and A. J. Majda, 2005: A new multiscale model for the Madden-Julian oscillation. J. Atmos. Sci., 62, 1694-1721.

Chao, W. C., 1987: On the origin of the tropical intraseasonal oscillation. J. Atmos. Sci., 44, 1940-1949.

Chen, S. S., R. A. Houze Jr., and B. E. Mapes, 1996: Multiscale variability of deep convection in relation to large-scale circulation in TOGA COARE. J. Atmos. Sci., 53, 1380-1409.

De Leon, Y., C. Erlick, and N. Paldor, 2010: The eigenvalue equations of equatorial waves on a sphere. Tellus, 62A, 62-70, doi:10.1111/j.1600-0870.2009.00420.x.

Emanuel, K. A., 1987: An air-sea interaction model of intraseasonal oscillations in the tropics. J. Atmos. Sci., 44, 2324-2340.

Gill, A. E., 1980: Some simple solutions for heat-induced tropical circulation. Quart. J. Roy. Meteor. Soc., 106, 447-462.

Hartmann, D., and H. H. Hendon, 2007: Resolving an atmospheric enigma. Science, 318, 1731-1732, doi:10.1126/science.1152502.

Held, I., and M. Suarez, 1994: A proposal for the intercomparison of the dynamical cores of atmospheric general circulation models. Bull. Amer. Meteor. Soc., 75, 1825-1830.

Hendon, H. H., and B. Liebmann, 1994: Organization of convection within the Madden-Julian oscillation. J. Geophys. Res., 99, 8073-8083.

— oscillation. J. Atmos. Sci., 51, 2225-2237.

Hsu, H.-H., B. J. Hoskins, and F.-F. Jin, 1990: The 1985/86 intraseasonal oscillation and the role of the extratropics. J. Atmos. Sci., 47, 823-839.

Kiladis, G. N., M. C. Wheeler, P. T. Haertel, K. H. Straub, and P. E. Roundy, 2009: Convectively coupled equatorial waves. Rev. Geophys., 47, RG2003, doi:10.1029/2008RG000266.

Lau, K. M., and D. E. Waliser, 2005: Intraseasonal Variability in the Atmosphere-Ocean Climate System. Praxis, 436 pp.

Liebmann, B., and D. L. Hartmann, 1984: An observational study of tropical-midlatitude interaction on intraseasonal time scales during winter. J. Atmos. Sci., 41, 3333-3350.

_ polated) outgoing longwave radiation dataset. Bull. Amer. Meteor. Soc., 77, 1275-1277.

Lin, J.-L., and Coauthors, 2006: Tropical intraseasonal variability in 14 IPCC AR4 climate models. Part I: Convective signals. J. Climate, 19, 2665-2690.

Madden, R. A., and P. R. Julian, 1972: Description of global-scale circulation cells in the tropics with a 40-50-day period. $J$. Atmos. Sci., 29, 1109-1123.

— , and - 1994: Observations of the 40-50-day oscillation-A review. Mon. Wea. Rev., 122, 814-837.

$\longrightarrow$, and —, 2005: Historical perspective. Intraseasonal Variability in the Atmosphere-Ocean Climate System, K. M. Lau and D. E. Waliser, Eds., Springer-Verlag, 1-18.

Majda, A. J., and J. Biello, 2004: A multiscale model for tropical intraseasonal oscillations. Proc. Natl. Acad. Sci. USA, 101, 4736-4741, doi:10.1073/pnas.0401034101.

— seasonal oscillations. Proc. Natl. Acad. Sci. USA, 106, $8417-$ 8422, doi:10.1073/pnas.0903367106.

Maloney, E. D., A. H. Sobel, and W. M. Hannah, 2010: Intraseasonal variability in an aquaplanet general circulation model. J. $A d v$. Model. Earth Syst., 2, doi:10.3894/JAMES.2010.2.5. 
Matsuno, T., 1966: Quasi-geostrophic motions in the equatorial area. J. Meteor. Soc. Japan, 44, 25-42.

Matthews, A. J., B. J. Hoskins, J. M. Slingo, and M. Blackburn, 1996: Development of convection along the SPCZ within a Madden-Julian oscillation. Quart. J. Roy. Meteor. Soc., 122, 669-688.

Nakazawa, T., 1988: Tropical super clusters within intraseasonal variations over the western Pacific. J. Meteor. Soc. Japan, 66, 823-839.

Neelin, J. D., I. M. Held, and K. H. Cook, 1987: Evaporation-wind feedback and low-frequency variability in the tropical atmosphere. J. Atmos. Sci., 44, 2341-2348.

Raymond, D. J., 2001: A new model of the Madden-Julian oscillation. J. Atmos. Sci., 58, 2807-2819.

Salby, M. L., and H. H. Hendon, 1994: Intraseasonal behavior of clouds, temperature, and motion in the tropics. J. Atmos. Sci., 51, 2207-2224.

Sobel, A. H., E. D. Maloney, G. Bellon, and D. M. Frierson, 2010: Surface fluxes and tropical intraseasonal variability: A reassessment. J. Adv. Model. Earth Syst., 2, doi:10.3894/ JAMES.2010.2.2.

Solodoch, A., W. Boos, Z. Kuang, and E. Tziperman, 2011: Excitation of intraseasonal variability in the equatorial atmosphere by Yanai wave groups via WISHE-induced convection. J. Atmos. Sci., 68, 210-225.

Straub, K. H., and G. N. Kiladis, 2003: Interactions between the boreal summer intraseasonal oscillation and higher-frequency tropical wave activity. Mon. Wea. Rev., 131, 945-960.

Waliser, D., and Coauthors, 2009: MJO simulation diagnostics. J. Climate, 22, 3006-3030.

Wang, B., 2005: Theories. Intraseasonal Variability in the AtmosphereOcean Climate System, K. M. Lau and D. E. Waliser, Eds., Praxis, 307-360.

, and H. Rui, 1990: Dynamics of the coupled moist KelvinRossby wave on an equatorial $\beta$ plane. J. Atmos. Sci., 47, 397-413.

Wheeler, M., and G. N. Kiladis, 1999: Convectively coupled equatorial waves: Analysis of clouds and temperature in the wavenumber-frequency domain. J. Atmos. Sci., 56, 374-399.

Zhang, C., 2005: Madden-Julian oscillation. Rev. Geophys., 43, RG2003, doi:10.1029/2004RG000158.

—, M. Dong, S. Gualdi, H. H. Hendon, E. D. Maloney, A. Marshall, K. R. Sperber, and W. Wang, 2006: Simulations of the MaddenJulian oscillation in four pairs of coupled and uncoupled global models. Climate Dyn., 27, 573-592.

Zou, J., and H.-R. Cho, 2000: A nonlinear Schrödinger equation model of the intraseasonal oscillation. J. Atmos. Sci., 57, 2435-2444. 